\title{
Understanding the Turkish biotechnology system through the functions of an innovation system
}

\section{Dilek Cetindamar}

School of Management,

Sabanci University,

Orhanli, Tuzla, 34956, Istanbul, Turkey

E-mail: Dilek@sabanciuniv.edu

\begin{abstract}
The paper empirically examines biotechnology innovation system in order to present the concerns of developing countries. Through mapping innovation processes/functions over time, it is possible to develop insights of the dynamics of innovation systems. This mapping is carried out for the Turkish biotechnology system, and the findings are summarised.
\end{abstract}

Keywords: Turkey; biotechnology; innovation system; functions.

Reference to this paper should be made as follows: Cetindamar, D. (2014) 'Understanding the Turkish biotechnology system through the functions of an innovation system', Int. J. Biotechnology, Vol. 13, Nos. 1/2/3, pp.105-119.

Biographical notes: Dilek Cetindamar is a Professor at Sabanci University. She received her BS degree from the Industrial Engineering Department, Boğaziçi University, her MA degree from the Economics Department, BU, and her PhD from the Management Department, Istanbul Technical University in 1995. She has participated in many international projects, including UN and EU projects. She has more than 50 publications, including 30 papers published in various international journals and nine books. She received an 'Encouragement Award' from Turkish Academy of Sciences in 2003. Her main interest and research topics are entrepreneurship and technology and innovation management.

This paper is a revised and expanded version of a paper entitled 'Understanding the internationalization of Turkish biotechnology system through the functions of an innovation system' presented at the 7th International Conference on Business Management and Economics, Turkey, 6 October 2011.

\section{Introduction}

Without a doubt, countries that have capabilities in developing and using biotechnology increase their competitiveness and bring welfare to their society. The use of advanced biotechnology by developing countries might further help to upgrade their existing industrial systems and make them more valuable and competitive.

How can such a critical technology be developed and implemented in developing countries? It is known that many studies on national innovation systems (NIS) are conducted theoretically and empirically for more than 20 years, and a significant amount of innovation policies are drafted (Nelson, 2007). NIS is considered to be the microcosm 
of some new technologies including biotechnology, and many studies attempted to understand how nations have tackled with the creation and development of systems where new technologies are embedded (Niosi and Bellon, 1994). The literature offers a specific approach to understand a particular technology in-depth: 'technological innovation system' (TIS) that studies the development, diffusion and utilisation of a specific new technology (Carlsson and Stankiewicz, 1991; Jacobsson and Bergek, 2006). Theoretically, TIS approach does not necessarily have a limitation based on a country since technologies might be developed in different countries, and there might be many interlinked agents operating in different national contexts. However, in practice, TIS approach is by and large implemented to analyse a particular country. Furthermore, both NIS and TIS-based studies are concentrated on advanced countries, developing the theory specific to the problems and priorities of those countries.

This paper aims to fill the void by analysing the Turkish biotechnology system, a technology in a developing country. To do so, the study will expand the idea of TIS by focusing on the processes of innovation systems (Jacobsson and Bergek, 2000). The 'functions of innovation system' approach helps to highlight the most important processes that need to take place in innovation systems in order to successfully lead to technology development and diffusion (Hekkert et al., 2007). After the detailed examination of key functions of the biotechnology system in Turkey, the paper will suggest policies to allow the system fulfil its functions and operate effectively and efficiently in order to both exploit and explore opportunities of biotechnology at the national level.

Even though it is not possible to create standard prescriptions valid for various countries, this paper aims to develop a solid understanding of how biotechnology and institutions co-evolve that might shed light to innovation policy issues for biotechnology across developing countries. Although the immediate goal is the Turkish policy makers, it will inevitably have policy implications for developing countries in general. The two key questions the study aims to investigate are:

1 the performance of the Turkish BT system

2 search for the weaknesses behind it so that the policy makers can be equipped with a broad perspective that will help to improve the performance of the Turkish BT

system.

The paper is based on four sections. After this introduction, Section 2 will briefly explain the methodology. Section 3 will present how Turkish biotechnology system functions, followed with a discussion section on the findings. Conclusion section summarises the implications of the study for the actors of the Turkish biotechnology system, and then concludes the paper with suggestions for further studies.

\section{Method}

Due to the difficulty of reaching public data on technology-based firms in Turkey, direct data collection through interviews is utilised. The starting point in identifying Turkish biotech firms was two previous biotechnology studies conducted in Turkey (Basaga and Cetindamar, 2000, 2006). This study updates these former studies which identified 50 and 90 biotechnology-related firms, respectively. The update is carried out in 2010 by 
searching associations and internet addresses of firms and newspapers. For example, Biotechnology Association has a database of biotechnology firms, but some of the firms in the list are not directly involved in biotech activities. Therefore, after a detailed analysis of each firm one-by-one, an updated list was formed involving 140 firms. The final list dropped to 120 when we called firms to get appointment for interviews and found that 20 of them went into bankruptcy.

We conducted interviews with the CEOs of 50 companies in the second half of 2010. Four of them were bankrupt firms, but the managers gave us valuable information on how the system worked or did not work. Five of these firms are not directly 'dedicated biotechnology' firms; in other words, currently they have minor biotechnology activities but they have plans to invest in technology, so we included them in our study (OECD, 2009). For example, an agricultural firm with 1,550 employees among which only 30 are working in biotechnology research for test purposes is also included in this study.

Besides firms, the study conducted interviews with other actors of innovation systems, namely five academicians and five managers in government agencies. These interviews allowed us to observe the dynamics of the biotechnology innovation system in Turkey.

\section{The performance of the biotechnology system}

An overview of the innovation system literature is presented to find out whether or not a shared understanding exists regarding which functions ought to be served in innovation systems. Based on this literature overview, the analysis of the biotechnology system is based on seven functions identified as the key of innovation systems to work:

1 entrepreneurial activities

2 knowledge development

3 knowledge diffusion through networks

4 the guidance of the search

5 market formation

6 resource utilisation

7 legitimacy (Hekkert et al., 2007; Jacobsson and Bergek, 2006; Bergek et al., 2008).

In this section, a brief description of each function will be followed by the empirical observation of that function in the Turkish case.

\subsection{Function 1: Entrepreneurial activities}

Entrepreneurs are able to identify, expand and exploit business opportunities; thus, they establish firms with varying activities due to their different competencies based on their resources, business line, market size and capabilities. That is why a nation's industrial structure determines the producer, buyer and supplier competencies that are imprinted in entrepreneurial activities.

The number of biotech firms in Turkey is still too small to reach a critical mass in order to generate positive synergies and spillovers, which could eventually set the 
foundations for an innovation-driven growth industry. With a population of 73 million, Turkey only has 120 biotech companies; whereas, Finland, with a population of 5 million, has 141 biotech companies (OECD, 2009).

The changes during the period of 2005-2010 clearly indicate two major developments. Firstly, the market growth mainly takes place in health applications as can be seen in Table 1. Secondly, the number of firms identified in the Turkish biotechnology market increased from 90 to 120 . However, it is important to highlight that 25 out of 120 firms are service firms selling international products in Turkey, so they have no production and R\&D in the country. What is meant by 'the number of firms' is all the firms that claim to have biotechnology applications among which only a small portion are dedicated biotech firms. According to our interviews and investigation of annual reports and internet sites, the dedicated biotech firms seem to be around 8 in 1999, 24 in 2005 and 50 in 2010.

Within the health sector, pharma firms form the majority but their operations are not biotechnology related. There are currently over 300 pharmaceutical companies in Turkey and just 43 manufacturing facilities, 14 of which are run by multinationals with no R\&D operations (TOBB, 2008). There is a recent trend of acquisitions of local firms by multinational firms in the pharmaceutical industry. For example, in July 2007, Czech firm Zentiva acquired 75\% of Eczacıbaşı Generic Pharmaceuticals' shares. In 2004, Actavis Group of Iceland acquired $90 \%$ of the shares of Fako, one of Turkey's leading pharmaceutical manufacturers. None of these international companies have declared plans about biotechnology-based production or research.

Hence, medical device companies are the dominant players in the Turkish biotechnology system: in $2010,55 \%$ of total biotech firms are in the field of medical equipment; $80 \%$ of 50 dedicated biotech firms are medical firms; $80 \%$ of 15 total spin-off companies from academia are medical firms; almost all of them have international trade; except one food company, all firms having international research connections are medical firms; and the largest companies among dedicated biotech firms are medical, employing more than 40 people while the majority of firms employ less than 10 . Overall, the dynamism of entrepreneurship lies in medical firms.

\subsection{Function 2: Knowledge development}

Knowledge spillovers act as a key mechanism that underlies new venture formation and development at the micro-level and economic growth at the macro-level (Agarwal et al., 2008). Thus, generation of new knowledge is a key element in emerging technologies like biotechnology.

The foresight study conducted by TÜBA (2004) (Turkish Science Academy) describes the biotechnology capabilities in Turkey. The report presents a detailed account of academic research in Turkey and the only available resource with actual data as of today. TÜBA identifies 137 research units working in the biotechnology field. These units are hosted in 71 faculty research institutions and four non-university research institutions. In these units, a total of 1970 researchers and experts work. The average number of employees per unit in Turkey is 15 , almost one fourth of the average in developed countries.

The TÜBA study clearly shows that publications increased in the field of biotechnology-based academic work from a very low starting point, but the patenting of these activities is incredibly low. A literature search of academicians publishing in 
internationally recognised journals indexed in SCI show that there are 4,517 papers published with Turkish scientists during the period of 1996-2008 (Niosi et al., 2012). Half of these papers were published in the last five years, and researchers from four universities (Hacettepe, Ankara, Ege and Middle East Technical University) constitute one third of them. More than half $(\% 56)$ of these papers are in the field of health biotechnology, while less than one fifth is about agriculture.

Besides universities, there are five major research institutes related to biotechnology.

The oldest and largest research institute in biotechnology research is the Genetic Engineering and Biotechnology Research Institute (GEBRI) established by the Turkish Technology and Scientific Research Council (TÜBİTAK) in 1983. Others are Şap Institute, Veterinary Control and Research Institute, Çukurova Advanced Agriculture Technologies Research and Development Institute, and Ankara Nuclear Agriculture \& Animal Research Centre.

Among these government-run research centres, Şap Institute and Veterinary Control and Research Institute have been the main vaccine producers in Turkey for many years. They are government-owned, and they are basically production oriented institutions. They sell their products in the national market. Private companies consider them as a competitor since they have experience and good networks. Almost all research institutes have established collaborations with university researchers (TÜBA, 2004).

The number of biotechnology patents in Turkey are almost negligible; around ten patents are issued in Turkey in 2005 (Basaga and Cetindamar, 2006). Following the international study's classification codes, we searched US patent database for the inventors and assignees who are cited as Turkish. There are 13 patents during the period of 1980-2009, nine of which were dated in the last three years (2007-2009). Turkish researchers are not assignees of these patents; assignees are from Italy, Germany, UK, Slovakia and the USA. All patents are in the field of health, and only one assignee is a firm while others are universities.

\subsection{Function 3: Knowledge diffusion through networks}

Networking might be partnering with upstream, downstream or peer companies, universities, centres of excellence, innovation professionals and others. Networks might bring many benefits to high technology-based firms, such as the transfer of tacit and explicit knowledge and tapping into market, technological, human, reputational, financial, and physical resources (Tolstoy and Agndal, 2010).

National and international bridging organisations are important actors in biotechnology development and diffusion. Since the early 1980s, the USA, European, and Japanese Governments have established special institutions for the development of biotechnology through networks between public and private partners.

In some developing countries such as Cuba, Brazil, Mexico, Thailand and Singapore, there are similar tendencies to set up specific institutions focused on biotechnology. Although most of these institutions are focused on scientific research, there are some that aim to encourage private sector participation in the development of biotechnology, such as the Center for Innovation and Technology in Mexico. This centre is a public/private corporation and tries to establish a link between industry and academia. Another quite successful country in building its biotechnology infrastructure is Singapore. The government set a clear strategic vision and established 'Biopolis' in 2004, a dedicated biomedical sciences R\&D hub which initiated an integrated countrywide research 
network connecting research institutes at the Biopolis with leading medical institutes, public hospitals and investigational medicine units (Ernst \& Young, 2010).

In Turkey, the Ministry of Health announced a new Project in 2010 to initiate research hubs through a new project labelled as 'Health Cities' (Dünya Gazetesi, 2010a). With this project, public private partnerships will be supported through funds in order to attract $R \& D$ and investment related to health sector in these cities, some of which are expected to be biotechnology related. In addition to the government initiative, there is a private initiative in İzmir (the fourth largest city in Turkey) which tries to pull together all actors (universities, government and companies) to establish a biotechnology cluster in İzmir. The goal is to attract both national and international investments. The city already has strong research universities and a number of internationally known Turkish biotech companies in the medical field.

A prestigious excellence centre in biotechnology is the Biotechnology Research and Application Centre, established within Ege University in 1998 with the EU funds. This centre is specialised in biotechnology studies and has very strong national and international networks. There are two spin-off companies resulted from the research of the Centre and 750 projects are in operation 40 of which are transferred into industry. The Centre received the 'best performing technology transfer centre' in the Enterprise Europe Network in 2008.

Some universities such as Ege and Bilkent University organise international conferences and conduct research with their international partners. Similarly, GEBRI is an institutional member of International Centre on Genetic Engineering and Biotechnology. According the information given in GEBRIs web page, the institution had 11 projects during the last decade, two of which have been financed by this international centre.

Besides national institutions, there are many institutions set up by international collaboration in which around 60 developing countries take part. These international research institutions, in general, are formed as a cooperation of research centres from South and North through tripartite agreements between technology owner, international breeding institute and donor. Institutions involved in these programmes are bilateral and multilateral aid agencies, international organisations, national agricultural research institutions, universities, private foundations and commercial companies.

The existing international networks indicate that developing countries face a low connectivity problem. This problem prevents them from utilising even the existing technological changes due to the failure of the diffusion mechanism. Many networks are isolated from each other, and there is no coordination of the efforts of various actors in the system. This is the main complaint in some of the international programmes. The same problem applies to the Turkish case as well.

\subsection{Function 4: Guidance of the search}

Guidance refers to the combined strength of factors influencing the search and investment behaviour. This might include sufficient incentives and/or pressures for them to undertake investments in an innovation system.

The successful developing countries in biotechnology field are the ones who have dedicated their resources to a limited number of technology fields; in other words, the research and investments are guided to a few specific areas rather than a wide selection of areas. For example, Brazil is known for agricultural biotechnology and biofuel. 
According to a 2009 survey by the International Service for the Acquisition of Agri-biotech Applications, Brazil has overtaken Argentina to become the world's second-largest user of genetically modified (GM) crops (Ernst \& Young, 2010). International companies such as Monsanto, Bayer and Syngenta are investors in agriculture. In addition, Brazil has been a global frontrunner in the development and adoption of biofuels as an alternate source of energy. As home to one-third of the world's sugarcane plantations, Brazil currently produces around 25 billion litres of ethanol annually from sugarcane and plans to increase production by as much as $150 \%$ by 2017 (Ernst \& Young, 2010).

Turkish Science and Technology High Commission (BTYK) are responsible for science and technology policy in Turkey since 1983. Its members include the President, two ministers and leaders and directors of government organisations such as the State Planning Organization. In its numerous meetings, biotechnology has been given high priority but most of the decisions taken have not been operationalised due to the lack of political commitment by governing parties. An example is the National Biosafety Law. Even though it has been on the agenda for almost nine years, it took its final form only in 2005, and then it was ratified by the Parliament in March 2010. The law to a large extent is a blueprint of the highly preventive EU biosafety regulations with additional restrictions put by the ruling party that plans to prevent stem cell research in particular. Thus, it is unlikely to stimulate more investment in agricultural biotechnology or critical pharmaceutical research.

\subsection{Function 5: Market formation}

New technology often has difficulty to compete with embedded technologies since most inventions are relatively crude and inefficient at the date when they are first recognised as constituting a new innovation. Thus, diffusion under these circumstances will necessarily be slow (Sharp, 1996).

The majority of developing countries do not have buyer firms (i.e., chemical and pharmaceutical industries), which is a prerequisite to the development of biotechnology competencies. For example, the lack of effective demand in the health care industry also prevents the development of biotechnology in the pharmaceuticals industry. In the majority of developing countries, the main industrial activity takes place in agriculture. Due to the importance of agriculture and the potential benefits of biotechnology in this industry, the direction of biotechnology applications leans more towards agriculture. On the other hand, the low education level of farmers, who are the main users, makes the successful application of biotechnology difficult as they cannot comprehend and implement complicated biotechnology products. This lack of competency is coupled with the lack of effective demand. This prevents the build-up of critical mass to drive the development of biotechnology. Moreover, similar to buyer industries, the competence of supplier industries is also limited, since they are either non-existent or very weak.

Turkey does not have a significant amount of technological infrastructure such as South Korea, Taiwan, and Singapore, but it has some agricultural and industrial research capacity. In addition, Turkey has a wide variety of local manufacturing capacities, the major ones being textiles, auto part industry, chemical and food. Thus, it might benefit from biotechnology, if it can succeed.

The size of the Turkish market where biotechnology products are used is given in Table 1. The total market size shows that unfortunately the previous study's (Basaga and 
Cetindamar, 2000) base scenario is actualised. Accordingly, base scenario expected that if nothing is done in biotechnology, biotechnology market will grow along the line of the natural economic growth which will be $5.2 \%$ per year, and it will reach US $\$ 1.75$ billion in 2010 (Basaga and Cetindamar, 2000). According to our calculation, the actual size of the total biotechnology market is realised as US\$1.77 billion in 2010 that is the confirmation of the expectation.

Table 1 Biotechnology market (million US dollars)

\begin{tabular}{lcc}
\hline Sector & 1999 & 2010 total production \\
\hline Health & 350 & $700^{*}$ \\
Agriculture & 0 & 0 \\
Food & 450 & 800 \\
Chemical & 30 & 60 \\
Environment & 100 & 185 \\
Others & 0 & 10 \\
Total & 950 & 1,773
\end{tabular}

Note: *Medical market only.

Source: Basaga and Cetindamar (2000) and updated data

Considering imports, the total market size in Turkey increased to US\$3.3 billion. Around US $\$ 0.3$ billion worth of bio enzymes and almost US\$1.2 billion bio-based health products (both pharmaceuticals and medical equipment) were imported and used in Turkey in 2010.

Among the sub-markets, health and food industries stand out as the drivers. However, the size of the food industry comes from traditional biotechnology products such as cheese, wine and beer. The only exception is the yeast producers. There is one yeast producer which is third largest producer in the world, and it has a very modern biotechnology laboratory with almost 30 scientists working in biotechnology projects.

Health industry is an important source for biotechnology development and diffusion for almost all countries. This is already apparent in advanced countries, but some developing countries successful in biotechnology, such as Cuba and Singapore, have established their biotechnology capacity on health industry. It seems like a biotechnology strategy in Turkey should certainly focus its strengths on health industry, particularly medical equipment segment. As discussed in function 1, medical firms are the ones who are highly dynamic in terms of internationalisation of their research and conducting R\&D with a reasonable number of patents.

Turkey has a potential for agriculture, but it cannot realise it due to its dedication to the EU regulations. Agricultural biotechnology applications comprise tools such as tissue culture, genetic engineering and molecular marker breeding. While plant tissue culture and plant molecular marker breeding are applied to some extent in universities and research institutions, no research projects are currently applying genetic engineering in plant breeding in Turkey. GM products are neither cultivated on Turkish soils, nor imported. The Ministry of Agriculture has allowed only a few test plantations of GM seeds of cotton, corn and potatoes in 2004. TÜBITTAK; nevertheless, predicts that biotechnology applications will become widely used and argues that Turkish agriculture, in particular, may benefit a lot from improved plant types, increased quality features and higher resistance to various environment conditions (i.e., drought) and disease 
(TÜBİTAK, 2004). However, there is no wide application of biotechnology in agriculture industry currently.

There are few biotechnology applications in the Turkish food industry. Even though biotechnology offers many opportunities to increase the functional qualities of food (e.g., higher content of essential vitamins and trace elements), the Turkish food producers are not investing in biotechnology applications in-house. This is because the majority of them are small-scale firms, and they are not capable of investing in new technologies, only $7 \%$ of them have invested in automation-based production (DPT, 2004). In turn, large-scale firms that use biotechnology prefer to import biotechnology-based ingredients, such as starter cultures, rather than to produce them in-house.

In 2000, there was no energy company in the field of biotechnology, but it started to flourish in five years as reported in 2006 (Basaga and Cetindamar, 2000, 2006). In the late 2000s, there were around 300 firms which mostly concentrated in biofuels, but with few exceptions these firms suspended their operations. Since the government raised the tax on biofuel so high, small firms were closed down while large facilities suspended their operations. In Turkey, biofuel makes up a mere share of $0.04 \%$ of the total national fuel consumption, but this can easily reach up to 30 to $40 \%$ if biofuel-promoting regulations in Europe could be adopted in Turkey.

Energy applications of biotechnology are increasing across the globe (Ernst \& Young, 2010), even though there is a slow down in other biotechnology applications due to financial crisis. To a large extend, Turkey depends on foreign energy sources. One third of Turkish electricity is generated from renewable resources including wind, solar and hydro energy, and this might increase if investments are supported. Biomass is one option where biotechnology can be applied to generate energy. In 2005, Turkish Energy Market Regulatory Agency issued regulations that provide incentives for investments in renewable energy generation, but the required regulatory changes took place in December 2010 (Dünya Gazetesi, 2006, 2010b). This might perhaps start the biotechnology applications in the energy sector in the near future.

Environment concerns are roaring at the global level, but there is not much development in improving the water and solid waste treatment conditions in Turkey. Industrial waste accounts for $55 \%$ of the total waste, but only $9 \%$ of it is treated (Enerji Bakanlığ (The Ministry of Energy), 2007). 11\% of industrial establishments have waste treatment facilities in their plants. Municipalities are lacking treatment facilities as well. Even though the market is big for biotech-based treatment products in Turkey, there is a lack of realisation resulting in the biotech firms directed to the environment market being very few.

\subsection{Function 6: Resources mobilisation}

Resources, both financial and human capital, are necessary as a basic input to all activities within an innovation system. For a specific technology, the allocation of sufficient resources by government as well as the companies is necessary to make knowledge production possible.

As human capital is discussed earlier during the analysis of function 2 (knowledge development), the focus in this section is on financial resources.

The distribution of loans and grants by government organisations for industrial research Turkish Technology Development Association (TTGV) invested in 240 technology projects during the period of 1991-2005 with a total investment of US\$95 
million where $7.2 \%$ of these funds were received by biotechnology projects (Basaga and Cetindamar, 2006). Another R\&D source for technology firms is Technology and Innovation Support Directorate (TEYDEB) operating under TÜBİTAK. During the period of 1996-2004, TEYDEB granted US\$ 219 million for 1303 projects, where biotechnology projects had a share of only $3 \%$ of the total funds.

Even though a small portion of government funds is allocated to biotechnology firms, there are relatively strong R\&D activities performed by biotechnology firms located in technoparks that have been initiated by government agencies including KOSGEB (the Small and Medium Sized Enterprise Development Directorate) since the second half of the 1990s. 20\% of the firms located in technoparks across different cities in Turkey are based on biotechnology. Technoparks are recent phenomena in Turkey, and the figure merely shows a positive trend of high technology activities that may look encouraging for the biotech industry.

Technopark-based firms (half of the firms in the sample) that are interviewed indicate that the key resource is government funds, but they complain about the lack of financial resources for growth. This explains why these firms are small, employing less than ten people and cannot afford any internationalisation activities. In fact, there are no special funds for biotechnology firms' growth or internationalisation. In addition, venture capital firms in Turkey are rare. It is considered that venture capital firms are the main strategic mechanism in linking biotech firms in networks and bringing international sales. However, having three firms which actually act like a private equity with late stage investments do not contribute to rapid growth and globalisation for biotech firms in Turkey. In fact, among those three so-called venture capital firms, one of them invested in only one medical firm in the last decade, which is not so promising for the development of biotechnology.

It is no surprise that most of the developing countries' financial institutions are weak, and most of the time venture capital firms are the missing elements in their financial markets. Only a few newly industrialising countries in Southeast Asia have succeeded in establishing a venture capital mechanism, mainly supported by their governments.

\subsection{Function 7: Creation of legitimacy/counteract resistance to change}

Legitimacy is a matter of social acceptance and compliance with relevant institutions; the new technology and its proponents need to be considered appropriate and desirable by relevant actors for resources to be mobilised, for demand to form and for actors in the new innovation system to acquire political strength (Jacobsson and Bergek, 2006; Bergek et al., 2008).

State policies can affect biotechnology through its impact on many aspects, including, taxes, funds given to research institutions and universities, rules on technology transfer agreements, technology and industry policies, and regulations regarding the research. Even though Turkish policy makers have identified biotechnology as a critical technology, available regulations do not support this. Just a recent example is the decree on biotechnology (Biosafety Law) that brings bureaucracy to any biotechnology research by making it compulsory to get permission for almost all activities in labs.

The major markets for biotechnology in Turkey are agriculture and health sectors; however, government regulations create a number of problems in both sectors. In the case of agriculture, Turkey complies with the EU laws, since it aims to become a member of its main trading partner, the EU. Hence, the regulatory adjustments are constraining the 
expansion of biotechnology into food and agriculture in Turkey due to Europe's highly preventive regulation of genetically modified organisms (GMOs) (Aerni and Bernauer, 2006). In the case of health sector, according to an international report, Turkish authorities are criticised for delays, for over two years, for marketing approvals of generic pharmaceuticals, which it claims has created uncertainty as to the status of protection of the undisclosed test or other data generated to obtain marketing approval for the pharmaceutical products involved (WPM, 2010). Medical firms also have three complaints about government regulations. First is the high taxes $(18 \%)$ imposed on the imported raw materials used in their companies whose products are taxed at a ratio of $8 \%$, leaving the burden of additional tax (10\%) to companies (TOBB, 2009). Second complaint is the delay of government approvals for medical products. Third one is the delay of payments to Turkish medical firms. Since $71 \%$ of health sector expenditures are paid by the government (due to its overall dominance in health insurance through the Social Security Institution), this is particularly a critical problem for innovative small firms that have limited financial sources. In fact, interviewed managers of the bankrupt firms indicated this as the most important problem.

The development of biotechnology requires regulations as well as the development of public trust in the technology (Aerni and Bernauer, 2006). Social and political institutions have an impact on biotechnology, since biotechnology is a unique technology in terms of its direct impact on human life and nature. Therefore, there are many social and political issues revolving around biotechnology the most important ones being safety, intellectual property rights and ethics.

The safety issue is crucial from the society's perspective. That is why many social and political groups are actively involved in biotechnology issues. Among industrialised countries, the most active countries in safety issue are in Europe where civil society has the strongest existence. European interest groups are very well organised, and they effectively influence the political mechanisms. For example, active involvement of animal associations and human rights groups has shaped the EC regulations, including the prohibition of the hormone application to animals.

There are a few Turkish platforms developed by academicians who are trying to inform the public about biotechnology. Two formal associations are mentioned in function 3. There are also semi-formal platforms such as Agbiyotek, a monthly journal that publishes papers about agricultural biotechnology and aims to prevent misinformation on GMOs.

In terms of intellectual property rights, even though patents were not traditionally used to protect living organisms, there has recently been an increasing tendency in the industrialised countries to provide patent protection to the biotechnology-based innovations. Therefore, many international organisations, such as the United Nations Industrial Development Organization (UNIDO), attempt to deal with the problems of accessing and controlling plant genetic resources and living organisms at the international level. Turkey signs UN agreements.

Another legitimacy issue is related to culture. For example, the phenomenon of spin off firms from academia in the USA is partly explained by the strong entrepreneurial culture of that country. The cultural environment in many European universities has not encouraged strong links between professors and the industry, and some universities have even had an anti-industrial attitude, and until recently researchers have had limited interest in setting up firms and pursuing financial rewards from it. 
The cultural atmosphere in Turkey and in many developing countries is similar to that in Europe. Out of 120 Turkish firms in 2010, only 15 are spin-off companies from universities. Special incentives and mechanisms need to be created in order to stimulate links with the industry; otherwise, the restricted resources of developing countries will be spent for basic science, which will then be transferred to foreign countries instead of reaching to the local economy. In the recent years, Turkish Government changed the involvement of academicians in technoparks and their right about having the credit of their inventions. This can be a good start.

\section{Concluding remarks}

The paper expands the functions of innovation framework in order to become dynamic, and focuses on the micro level in the analysis of innovation systems. It empirically applies TIS approach and examines the Turkish biotechnology system. Based on the seven key functions identified in the literature, this paper takes the concerns of the developing countries into consideration. The goal is to understand not only the structure, but also the dynamics of institutions and the interactions between actors of the innovation systems that will result in successful technology exploration and exploitation activities.

The overall analysis of the changes in the Turkish biotechnology system during the period of 2000-2010 indicates a lost decade for Turkey. The main assumption laid down in the 2000 report was 'no change at all' (Basaga and Cetindamar, 2000). In other words, the expectations included; "the government will not have a specific policy with regards to biotechnology; government will not provide incentives to biotech producers; it will not prepare effective regulations; and it will not approve the use of biotechnology in agriculture". They are all realised and the share of biotechnology in total economy remained almost the same in ten years.

\subsection{Implications for firms}

Biotech firms constitute a small segment of the Turkish economy currently. However, given the growth expectations of the country and its crowded population, there is a potential growth for them that might start to build a critical mass. Firms should learn the prospects and the evolution of biotechnology within the country and abroad to adjust their strategies. It seems that the health sector, which is highly under the control of imports, might become a good candidate industry for biotech firms. Government supports announced for 'Health Cities' and R\&D incentives offered should be a good prospect for biotech firms to enter this field and develop competencies.

\subsection{Implications for research organisations}

It is necessary to improve networks by organising the cooperation of institutions and firms. The strengthening of cooperation in biotechnology is crucial for many reasons. First of all, biotechnology is a multidisciplinary technology integrating biochemistry, microbiology, bioprocessing and chemical process technology. This integration of disciplines and skills is by no means easy to achieve, since it requires new forms of organisation and structuring of firms and institutions. Second, biotechnology firms need 
to coordinate the management, $\mathrm{R} \& \mathrm{D}$, marketing and distribution activities and become expert in all these dimensions.

Turkey, like many developing countries, should not only increase the connectivity among national firms and institutions, but also should gain expertise in increasing the efficiency of technology transfer at the global level. Developing countries may take advantage of joint-research ventures with either industrialised countries or other developing countries.

\subsection{Implications for policy makers}

Turkish Government should improve the receiver competence by deciding on the type of biotechnology industry that the national policies will target. Just like any other developing country, Turkey does not have the luxury of spending or risking its resources on dead ends. Thus, there are only a few paths to follow for biotechnology development. For Turkey a potential route may be to concentrate on building capabilities in well-established, proven and relatively simpler techniques in medical industry as the bulk of competence is already in this sector. The best example of this route is Brazil whose ethanol programme relied on known fermentation technologies.

Whatever route of development and products are chosen for the Turkish biotechnology system, long-term, stable and strong policies will be needed. This is particularly important for building infrastructure, especially training of scientific and technical manpower. In biotechnology, scientists and researchers need to be experts not only in their field, but also in various interdisciplinary fields. The complementary skills are especially important for the adaptation and absorption of technology transferred, since biotechnology has a significant tacit character and more importantly very location-specific technology. This means that biotechnology applications are dependent on certain environmental conditions and need to be adapted to local conditions. That is why biotechnology necessitates an intensive adaptive research capability and continuous learning. This, in turn, increases the requirements for receptive competence of firms and researchers in developing countries. Considering that developing countries will need to import many biotechnology products, strengthening receptive competence becomes crucial for success. To do so, they need to be able to communicate with other scientists and exchange knowledge. It is also important to exploit the existing knowledge published in journals or available in databases. However, this is not easy, since it requires library support, multimedia training systems, electronic libraries and cooperation with other countries and scientists. Developing countries should increase their competence level by using all possible ways, including sending scientists to be trained in industrialised countries.

Political will and commitment are important elements since they influence the long-term strategies in starting and developing a biotechnology system. Having regulatory infrastructure including protection of intellectual property rights is one of the early steps in encouraging the development of local technologies and making use of the rich biodiversity in Turkey. The recent regulation about biodiversity that was forwarded to the Parliament in November 2010 receives many critics about allowing destruction of biodiversity.

In short, the potential advantages of biotechnology applications in Turkey can only be realised, if all the actors of the biotechnology system (firms and organisations) work together with a long-term strategy perspective (Cetindamar and Carlsson, 2003). It would 
enable Turkey to create its home-grown biotechnology capabilities and become better integrated in the global knowledge economy.

\section{Acknowledgements}

The author is grateful to the TUBITAK grant $(109 \mathrm{~K} 178)$ that made this study possible.

\section{References}

Aerni, P. and Bernauer, T. (2006) 'Stakeholder attitudes toward GMOs in the Philippines, Mexico, and South Africa: the issue of public trust', World Development, Vol. 34, No. 3, pp.557-575.

Agarwal, R., Audretsch, D. and Sarkar, M.B. (2008) The Process of Creative Construction: Knowledge Spillovers, Entrepreneurship and Economic Growth, Jena Economic Research papers, 2008-008.

Basaga, H. and Cetindamar, D. (2000) Uluslararası Rekabet Stratejileri: Biyoteknoloji Raporu (International Competition Strategies: Biotechnology Report), TÜSİAD, İstanbul.

Basaga, H. and Cetindamar, D. (2006) Türkiye'de Biyoteknoloji Işsirlikleri (Biotechnology Collaborations in Turkey), TÜSİAD, İstanbul.

Bergek, A., Jacobsson, S., Carlsson, B., Lindmark, S. and Rickne, A. (2008) 'Analyzing the functional dynamics of technological innovation systems: a scheme of analysis', Research Policy, Vol. 37, No. 3, pp.407-429.

Carlsson, B. and Stankiewicz, R. (1991) 'On the nature, function, and composition of technological systems', Journal of Evolutionary Economics, Vol. 1, No. 2, pp.93-118.

Cetindamar, D. and Carlsson, B. (2003) 'Biotechnology and implications for capability building in developing countries', in Reddy, P. (Ed.): Technology Transfer for Sustainable Development, Encyclopedia of Life Support Systems (EOLSS), EOLSS Publishers, Oxford, UK [online] http://www.eolss.net (accessed 2 May 2007).

DPT (2004) Sector Profiles of Turkish Industry. DPT, Ankara.

Dünya Gazetesi (2006) Tarım Sektörü Özel Sayısı (Special Issue on Agriculture Sector), Dünya Gazetesi, 27 April.

Dünya Gazetesi (2010a) Medikal Sektör Raporu (Special Issue on Medical Sector), 12 March.

Dünya Gazetesi (2010b) Enerji Sektörü Özel Sayısı (Special Issue on Energy Sector).

Enerji Bakanlığı (The Ministry of Energy) (2007) Türkiye İklim Değişikliği Birinci Bildirimi (The First Declaration Report on Turkish Climate Change), Enerji Bakanlığı, Ankara.

Ernst \& Young (2010) Beyond Borders Global Biotechnology Report, New York.

Hekkert, M.P., Suurs, R.A.A., Negro, S.O., Kuhlmann, S. and Smits, R.E.H.M. (2007) 'Functions of innovation systems: a new approach for analysing technological change', Technology Forecasting and Social Change, Vol. 74, pp.413-432 [online] http://www.imshealth.com/ portal/site/imshealth/ (accessed 20 February 2012).

Jacobsson, S. and Bergek, A. (2006) 'A framework for guiding policy-makers: intervening in emerging innovation systems in 'catching-up' countries', The European Journal of Development Research, Vol. 18, No. 4, pp.687-707.

Nelson, R.R. (2007) 'Institutions and economic growth: sharpening the research agenda', Journal of Economic Issues, Vol. 41, No. 2, pp.313-323.

Niosi, J. and Bellon, B. (1994) 'The global interdependence of national innovation systems evidence, limits, and implications', Technology in Society, Vol. 16, No. 2, pp.173-197.

Niosi, J., Hanel, P. and Reid, S. (2012) 'The international diffusion of biotechnology: the arrival of developing countries', Journal of Evolutionary Economics, Vol. 22, No. 4, pp.767-783. 
OECD (2009) The Bioeconomy to 2030: Designing a Policy Agenda, OECD, Paris.

Sharp, M. (1996) The Science of Nations: European Multinationals and American Biotechnology, STEEP Discussion paper No. 28, University of Sussex, Brighton.

TOBB (2008) Türkiye İlaç Sanayi Raporu (Turkish Pharmaceutical Industry Report), TOBB, Ankara.

TOBB (2009) Türkiye Medikal Sanayi Raporu (Turkish Medical Industry Report), TOBB, Ankara.

Tolstoy, D. and Agndal, H. (2010) 'Network resource combinations in the international venturing of small biotech firms', Technovation, Vol. 30, pp.24-36.

TÜBA (2004) Moleküler Yaşam Bilimleri ve Teknolojileri Öngörü Raporu (2003-2023) (Foresight Report about Molecular Life Sciences and Technologies), TÜBA, Ankara.

TÜBİTAK (2004) Vizyon 2023 Projesi Tarım ve Gida Paneli Çalışmaları (Vision 20023 Project's Agriculture and Food Panel), TÜBİTAK, Ankara.

World Pharmaceutical Market (WPM) (2010) Turkey 2010, Espicom. 